\title{
Improving Puskesmas Staff Competency Through Office Application Workshop At Puskesmas Selindung
}

\author{
Wishnu Aribowo Probonegoro1, Lili Indah Sari 2, Sujono³, Ellya Helmud4 \\ 1,3,4 Information Systems Study Program, Faculty of Information Technology, ISB Atma Luhur \\ 2Informatics Management Study Program, Faculty of Information Technology, ISB Atma Luhur \\ Email: wishnuap77@atmaluhur.ac.id¹, lilie@atmaluhur.ac.id², sujono@atmaluhur.ac.id³, \\ ellyahelmud@atmaluhur.ac.id ${ }^{4}$ \\ doi https://doi.org/10.36526/gandrung.v2i2.1338
}

\begin{abstract}
Puskesmas is a health service agency that provides health services to the community, in dire need of speed of information service so that it can provide optimal service to the community. To provide optimal service to the community, the puskesmas needs to increase the competence of its staff, by conducting office application workshops for its staff. For the puskesmas staff in Selindung, there are already some who know how to use office applications such as word, excel and powerpoint. But in their use and utilization in more detail and quickly, they still do not understand and are not optimal. This is what makes the author and the team collaborate with the Puskesmas Selindung to conduct office application workshops for puskesmas staff. The purpose of this workshop is to increase the competence of puskesmas staff in the use and use of computers, especially in office applications, including Microsoft Word, Microsoft Excel and Microsoft PowerPoint. Because these three applications are often used for data and information needs managed by the Selindung health center. The method used in this activity is a workshop and training model. That is by conducting lectures or giving material, and directly practised
\end{abstract}

Keyword: Office applications, staff competence, use of computers, Puskesmas selindung, workshop

\section{Pendahuluan}

Era globalisasi dan komputerisasi saat ini berkembang pesat saat ini khususnya perkembangan ilmu pengetahuan dan teknologi informasi yang semakin maju, maka sangat diperlukan suatu kemampuan (skill) yang memadai guna mendukung kinerja para staff atau karyawan di suatu instansi. (Niati et al., 2019) Kebutuhan akan terknologi informasi merupakan hal yang tidak bisa dihindari di berbagai sector bidang dan kehidupan, karena kemajuan teknologi informasi dan komputer sebagaii pendukung pemrosesan data dan informasi telah menjadi kebutuhan pokok dalam suatu instansi. Instansi jasa pelayanan yang memberikan pelayanan kepada masyarakat, sangat membutuhkan kecepatan pelayanan informasi sehingga dapat memberikan pelayanan yang optimal kepada masyarakat.(Risnawati et al., 2020)

Pusat Kesehatan Masyarakat yang selanjutnya disebut Puskesmas adalah fasilitas pelayanan kesehatan yang menyelenggarakan upaya kesehatan masyarakat dan upaya kesehatan perseorangan tingkat pertama, dengan lebih mengutamakan upaya promotif dan preventif, untuk mencapai derajat 
GANDRUNG: Jurnal Pengabdian Kepada Masyarakat ISSN: 2721-6136 (Online)

kesehatan masyarakat yang setinggi-tingginya di wilayah kerjanya.(Kesehatan, 2014). Puskesmas sebagai jasa pelayanan kesehatan, membutuhkan komputer sebagai alat pemrosesan dan penyajian informasi, begitu juga di puskesemas Selindung(Ali et al., 2018). Puskesmas Selindung merupakan salah satu puskesmas yang ada di kota Pangkalpinang, tepatnya di kecamatan Gabek yang beralamatkan di Jl. Jend. Sudirman, Selindung. (Google, n.d.) Untuk memberikan pelayanan yang optimal dan maksimal kepada masyarakat,pihak puskesmas membutuhkan peningkatan kompetensi terhadap staf staf di puskesmas dengan cara melakukan workshop aplikasi perkantoran bagi sstaf nya.

Menurut (Wayne, 2008) menyatakan bahwa pelatihan dan pengembangan (training and development) merupakan jantung dari upaya berkelanjutan untuk meningkatkan kompetensi karyawan dan kinerja organisasi. Di dalam melalukan pelatihan akan diperoleh pengetahuan dan keterampilan yang dibutuhkan untuk pekerjaan sehingga dapat didayagunakan secara optimal melalui terciptanya suatu kondsi tenaga kerja yang memenuhi semboyan The Right Man On The Right Job At The Right Time yaitu tepat orang, tepat pekerjaan dan tepat waktu yang semuanya dapat mendukung manajemen kinerja organisasi. (Wayne, 2008).Penelitian sejenis pernah dilakukan juga di PMI Kota Tarakan, untuk meningkatkan Sumber Daya Manusia (SDM) PMI Kota Tarakan masih membutuhkan berbagai keterampilan dalam menggunakan komputer, khususnya terkait dengan aplikasi pengolah kata dan angka yang sederhana, terutama dalam membuat laporan dan berbagai jenis surat masih membutuhkan berbagai keterampilan dalam menggunakan komputer, khususnya terkait dengan aplikasi pengolah kata dan angka yang sederhana, terutama dalam membuat laporan dan berbagai jenis surat. (Fadlan \& Saputra, 2020).Dalam melakukan aktivitas pelayanan kepada masyarakatnya, para perangkat desa Wirogunan masih belum memanfaatkan potensi yang dimiliki secara maksimal dalam mengoperasionalkan program Microsft Office, khususnya Microsoft excel. Kondisi ini tentunya berdampak terhadap kurang maksimalnya kinerja perangkat desa di dalam melakukan tugasnya.(Ningsih \& Dewi, 2020). Salah satu cara yang dapat dilakukan untuk mengatasi permasalahan adalah melakukan pelatihan komputer dengan menggunakan aplikasi Microsoft Office Word dan Excel (Yusril et al., 2015)

Aplikasi perkantoran seperti microsft word, excel dan powepoint merupakan aplikasi yang sering digunakan oleh staff puskesmas Selindung dalam mengelola informasi dan data yang ada. $\mathrm{Di}$ dalam penggunaan aplikasi perkantoran ini tidak semua staff memahami, mengetahui fitur dantools yang tersedia di word, excel powerpoint. Hanya fitur dan tools yang sederhana saja yang mereka ketahui, seperti untuk menyimpan, mencetak, penggunaan tulisan, dan pengaturan ukuran kertas. Untuk fitur atau tools yang lebih rinci lagi mereka masih kurang paham untuk menggunakannya. Pada 
GANDRUNG: Jurnal Pengabdian Kepada Masyarakat ISSN: 2721-6136 (Online)

microsftwordseperti pembuatan tabel yang digabung, pembuatan border dan shading, menyisipkan gambar, membuat header dan footer serta pembuatan mail merge (surat masal) mereka belum pernah menggunakannya, mereka masih melakukan satu persatu. Padamicrsoft word ada yang namanya mail merge (surat massal) (Susilo et al., 2020), membuat satu surat, tapi bisa untuk banyak orang atau instansi yang dituju. Didalam membuat grafik dan tabel masih ada kesulitan yang mereka hadapi.Penggunaan microsft exce/hanya digunakan untuk mengelola angka dan data seperti pengelolaan data keuangan, data pasien dan lainnya..Staff puskesmas masih belum mengetahui dan paham terhadap toolsdan fitur untuk melakukan kalkulasi yang ada di microsft excel, penggunaan microsft excel belum maksimal digunakan. Seperti dalam melakukan penjumlahan atau mencari nilai rata rata,staff ini masih menggunakan kalkutor untuk mengetahui hasilnya, dengan microsft exce/kita bisa menggunakan rumus dan formula untuk melakukan pengolahan angka. Penggunaan microsft powerpoint untuk membuat presentasi masih sederhana sekali yang di buat oleh staff puskesmas hanya berupa tulisan,menambhakan slide dan menyisipkan gambar. Pada microsft powerpoint kita bisa menambahkan suara, animasi, efek, desain dan yang lainnya, sehingga file presentasi yang dibuat dan ditampilkan nantinya akan jauh lebih atraktif dan menarik.

Hal inilah yang membuat penulis dan team mengadakan kerjasama dengan pihak puskesmas selindung untuk melakukak worksshop aplikasi perkantoran bagi staff puskesmas. Tujuan dilakukan worksop ini agar bisa meningkatkan kompetensi dan ketrampilan staff puskesmas dalam mengoperasikan dan penggunaan komputer khususnya pada aplikasi perkantoran diantaranya microsft word, microsft excel dan microsft powerpoint.Karena ke tiga aplikasi ini sudah dan sering dipakai untuk kebutuhan data dan informasi yang dikelola oleh puskesemas selindung.

\section{Metode}

Kegiatan Pengabdian Masyarakat ini dilakukan di Puskesmas Selindung yang bealamat di Jl. Jend. Sudirman, Selindung, kecamatan Gabek, kota Pangkalpinang..Kegiatan ini berlangsung selama 3 hari yaitu dari tanggal 3 September 2018 sampai dengan tanggal 5 September 2018.

Ada beberapa tahapan dalam melakukan pengabdian masyarakat ini kepada puskesmas Selindung diantaranya yaitu :

1. Tahap Persiapan

Pada Tahap ini dibagi mejadi 2

a. Tahap Pra Kegiatan ( Sebelum Kegiatan) 
Pada Tahap ini, penulis dan team serta dukungan dari pihak LPPM ISB(Institut Sains dan Bisnis) Atma Luhur melakukan kunjungan dan observasi terhadap kebutuhan teknologi informasi apa saja yang dibutuhkan dan sering di pakai untuk memenuhi kebutuhan informasi yang ada di Puskesmas Selindung. Setelah mecapai suatu kesepakatan terhadap kebutuhan informasi, bahwa pihak puskesmas selindung meminta untuk melakukan workshop atau pelatihan Aplikasi Perkantoran untuk staff puskesmas agar bisa memberikan pelayana yang optimal

\section{b. Tahap Penyesuaian Jadwal Workshop}

Pelaksanaan waktu workshop disesuaikan dengan permintaan pihak puskesmas Selindung yaitu di mulai dari jam 13.00 wib sampai dengan jam 17.00 wib. Hal ini dikarenakan pagi hari nya masih memberikan pelayanan kesehatan kepada masyarakat

\section{Tahap Pelaksanaan}

Metode yang dilakuan dalam kegiatan ini adalah model workshop dan pelatihan. Yaitu dengan melakukan ceramah atau pemberian materi, dan praktek langsung, Metode ceramah dan tanya jawab digunakan untuk memperkenalkan pengetahuan dan keterampilan yang diberikan. Pada saat workshop berlamgsung, jika ada peserta yang kurang paham atau tidak mengerti bisa langsung ditanyakan. Tanya jawab juga berfungsi untuk mengetahui sejauh mana pemahaman peserta terhadap materi yang sudah diberikan.(Sari et al., 2021)Narasumber pada pengabdian masyarakat ini adalah Dosen ISB Atma Luhur dan dibantu oleh beberapa mahasiswa ISB Atma Luhur.Pada Saat praktek langsung, jika peserta mengalami kendala atau kesulitan, narasumber dan mahasiswa juga membantu agar peserta workshopini mengerti dan paham.

Dalam Pelaksanannya tahapan ini di bagi ke dalam beberapa langkah selama 3 hari, setiap harinya berbeda materi.

a. Hari pertama

Pada pelatihan hari pertama penulis dalam hal ini Narasumber memberikan materi tentang Microsft Word.Microsoft Word merupakan salah satu perangkat lunak yang telah banyak digunakan karena kemudahan dalam pengoperasiannya. Perangkat lunak ini juga mampu memberikan berbagai macam fitur yang dapat digunakan oleh pengguna dalam membantu menyelesaikan berbagai pekerjaan terkait dengan pengolahan kata dengan mudah. (Yusril et al., 2015)

Microsoft Wordyang diajarkan meliputi penulisan didalam word, pengaturan margin, tabulasi, menyispkan gambar, bentuk serta pembuatan surat massal. 


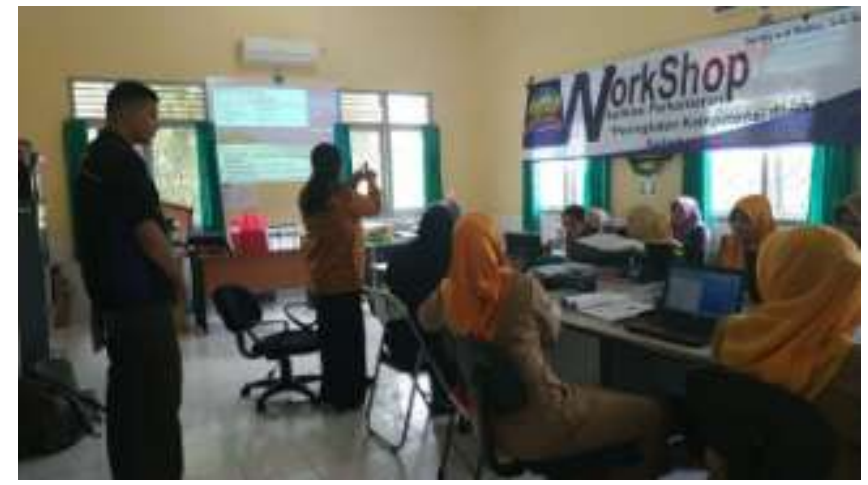

Gambar 1. Pemateri sedang memberikan penjelasan materi

Untuk materi apa saja yang diberikan pada workshop ini , bisa dilihat pada tabel di bawah ini :

Tabel 1. Pemberian Materi Microsft Word

\begin{tabular}{|c|c|c|}
\hline Hari & Workshop & Materi \\
\hline $\begin{array}{c}\text { Senin } \\
3 \text { September } \\
2018\end{array}$ & $\begin{array}{l}\text { Workshop Aplikasi } \\
\text { Perkantoran } \\
\text { Word }\end{array}$ & $\begin{array}{l}\text { - } \text { Pengenalan Ms. Word } \\
\text { - } \text { Format Penulisan } \\
\text { - Penyisipan Tabel } \\
\text { - } \text { Format Tabel } \\
\text { - } \text { Section dan Page Break } \\
\text { - Penyisipan Gambar } \\
\text { - Penyisipan ClipArt } \\
\text { - Penyisipan WordArt } \\
\text { - Penyisipan Grafik } \\
\text { - Penyisipan Shapes } \\
\text { - Penyisipan SmartArt } \\
\text { - Penyisipan Waktu } \\
\text { - Penyisipan Objek } \\
\text { - Penyisipan Equation } \\
\text { - Penyisipan Simbol } \\
\text { - } \text { Dokumen Berkolom } \\
\text { - } \text { Mail Merge }\end{array}$ \\
\hline
\end{tabular}

b. Hari KeDua

Microsoft Excel merupakan sebuah program aplikasi yang lembar kerjanya terdapat fitur kalkulasi dan pembuatan grafik sehingga menjadikan salah satu program komputer yang populer digunakan di dalam komputer mikro hingga saat ini.(Adzim \& Rum, 2017). Tujuan dari pemanfaatanaplikasi Microsoft Excel ini adalah untuk membantu dan mendukung menyelesaikan pekerjaan dengan lebih mudah, cepat, akurat dan efisien (Malabay, 2016). Materi Microsft Excel yang diajarkan di hari 
GANDRUNG: Jurnal Pengabdian Kepada Masyarakat ISSN: 2721-6136 (Online)

kedua yaitu pengenalan excel, pengolahan data, pembuatan border, penggunaan rumus dasar dan formula untuk melakukan perhitungan, penggunaan fungsi fungsi yang ada diMicrosft Excel, dan lainnya

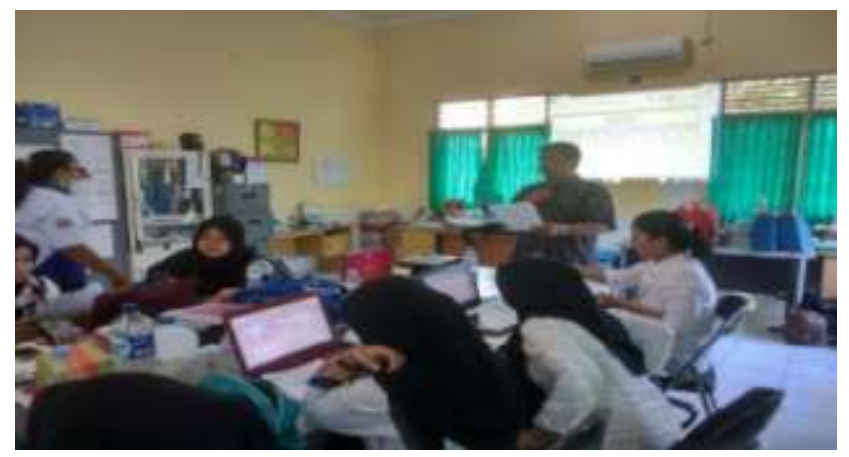

Gambar 2. Pemateri sedang memberikan materi dan latihan excel

Tabel 2. Pemberian Materi Microsft Excel

\begin{tabular}{ccl}
\hline Selasa & Workshop Aplikasi & Pengenalan Excel \\
\cline { 2 - 4 } 4 September 2018 & Perkantoran & Pembuatan tabel, border and shading \\
& Excel & Penggunaan rumus dan operasi \\
& & aritmatik seperti yaitu $+,-, I, *$, sum, \\
& average, min, max, hingga count \\
& - Pembuatan grafik dan tabel di excel \\
& $-\begin{array}{l}\text { Penggunaan fungsi logika di dalam } \\
\text { rumus }\end{array}$ \\
& - Penggunaan vlookup dan hlookup \\
\hline
\end{tabular}

\section{c. Hari Ketiga}

Microsoft powerpoint merupakan aplikasi software yang dapat digunakan untuk menyampaikan materi berupa tulisan, gambar bentuk, foto, aneka warna dan jenis tulisan, fitur hyperlink, audio, video, dan animasi. Powerpoint merupakan media yang digunakan untuk menyampaikan poinpoin pokok dari materi yang kita sampaikan dengan fiturfitur yang menarik. (Nurhidayati et al., 2019). Materi Powerpoint yang diajarkan narasumber pada hari ketiga diantaranya pengenalan powepoint, menambahkan slide, membuat efek animas, tulisan, desain dan memasukan suara. Para peserta workhop ini diharapkan mampu memahami segala fungsi toolbar dan menu bar yang ada dalam Microsoft office PowerPoint(Permata et al., 2021) 
GANDRUNG: Jurnal Pengabdian Kepada Masyarakat ISSN: 2721-6136 (Online)

Tabel 3. Pemberian Materi Microsft Powerpoint

\begin{tabular}{|c|c|c|}
\hline $\begin{array}{l}\text { Rabu } \\
5 \text { September } 2018\end{array}$ & $\begin{array}{l}\text { Workshop Aplikasi } \\
\text { Perkantoran } \\
\text { Powerpoint }\end{array}$ & $\begin{array}{l}\text { - } \text { Pengenalan Powerpoint } \\
\text { - } \text { Penyisipan gambar, tabel, grafik } \\
\text { - Penggunaan efek design } \\
\text { - Penggunaan animasi tulisan, gambar } \\
\text { - } \text { Menambahkan efek suara } \\
\text { - Penggambungan atau menyambung } \\
\text { slide }\end{array}$ \\
\hline
\end{tabular}

\section{Tahap Evaluasi}

Setiap selesai memberikan materi, peserta diberikan soal soal praktek dan tugas untuk mengerjakan latihan tersebut, sesuai dengan materi yang diberikan oleh narasumber. Terkadang soal yang diberikan berdasarkan kendala yang sering dihadapi oleh staff puskesmas.Diakhir pertemuan peserta juga diberikan seperti tugas untuk di rumah dan dikumpulkan keesokan harinya dengan menggunakan flashdisk. Tujuan Pemberian tugas ini untuk mengetahui seberapa jauh peserta sudah mengerti apa yang sudah di praktekan. Oleh karena itu pemahaman, penguasaan, penerapan aplikasi sangat diperlukan dalam rangka meningkatkan produktivitas dan komptensi yang dimiliki oleh staff puskesmas Tujuan Workshop ini yaitu membantu dan mendukung menyelesaikan pekerjaan dengan lebih mudah, cepat, akurat dan efisien.

\section{Hasil dan Diskusi}

Kegiatan Pengabdian Masyarakat ini, di lakukan di ruang rapat puskesmas Selindung.Dimana peserta kegiatan ini yaitu para staff puskesmas dan juga tenaga medis yang berjumlah 16 orang. Sebelum dimulai nya kegiatan, dilakukan beberapa persiapan diantaranya persiapan alat dan bahan workshop.Selama berlangsung workshop ini, masing masing peserta ada yang membawa laptop masing masing, ada juga yang tidak memiliki laptop. Bagi yang tidak memiliki laptop, pihak ISB( Institut Sains dan Bisnis) Atma Luhur menyediakan beberapa laptop untuk di bawa pada saat kegiatan workshop ini. Hal ini bertujuan agar setiap peserta bisa langsung mempraktekan secara langsung dan mengimplementasikan apa yang disampaikan narasumber. Kalaupun ada kendala para peserta bisa langsung memperbaiki kesalahan yan terjadi di bantu oleh narasumber atau para mahasiswa yang siap membantu. 


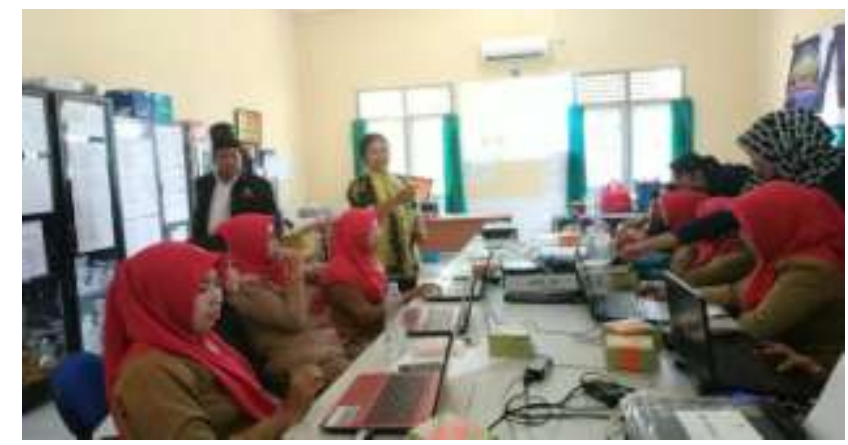

Gambar 3. Pemateri sedang memberikan penjelasan terhadap perserta yang bertanya

Peserta sudah sering menggunakan aplikasi perkantoran untuk kebutuhan informasi yang dibutuhkan oleh puseksmas, tetapi ada beberapa yang tidak paham dan terkadang harus manual. Seperti pembuatan surat massal, masih dilakukan satu persatu dengan format yang sama, padahal jika menggunakan mail merge, satu format surat bisa di tujukan untuk banyak orang atau instansi yang dituju. Pembuatan tabulasi seperti membuat halaman daftar isi masih menggunakan manual yaitu menekan tombol titik titik berulang ulang, padahal bisa menggunakan tabulasi.

Saat pemberian materi excel dan powerpoint banyak mengalami kesulitan dan masih banyak yang kurang paham, sehingga di dalam penyampain materi dan praktek harus perlahan lahan dan diulang guna menjelaskannya secara rinci. Para peserta sudah menggunakan excel pada saat pengolahan data, namun sering menghitung ulang dengan kalkulator, hal ini akan memperlambat. Dan tidak efektif.Dengan diajarkannya penggunaan rumus aritmatik, logika dan beberapa fungsi yang ada di excel, di harapkan para peserta bisa membuat laporan dengan maksimal dan menghemat waktu tanpa harus menggunakan kalkulator. Pada saat materi poweporint, peserta hanya membuat slide secara sederhana, terkadang untuk menambahkan efek desain atau tulisan berbentuk animasi masih kurang paham.Para peserta belum sepenuhnya mengetahui dan menggunakan fitur dan tools yang ada pada powerpoint seperti emberikan animasi, desain, tulisan bergerak,menyisipkan suara, menggabungkan slide dan lainnya. Dengan adanya pemberian materi powerpointkepada peserta, diharpkann peserta mampu untuk membuat presentasi yang baik, atraktif dan memiliki daya tarik kepada masyarakat. 


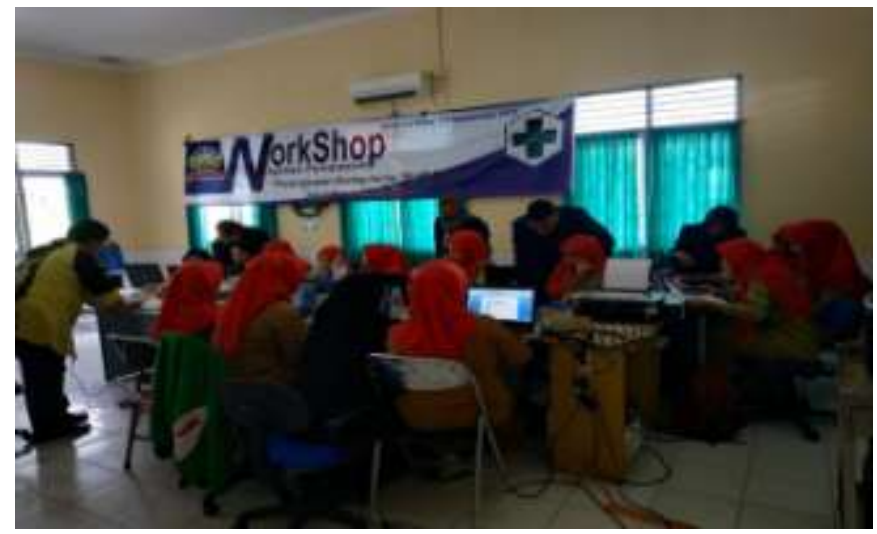

Gambar 4. Pemateri dan mahasiswa memberikan bantuan pendampingan terhadap perserta

. Pada saat workshop berlangsung, para peserta memiliki semangat yang luar biasa dan aktif dalam mengikuti kegiatan ini.Workshop yang dilakukan di Puskesmas Selindung ini di mulai dari siang hari sampai dengan sore, dikarenakan pagi hari nya staff dan tenaga kesehatan yang di Puskesmas Selindung memberikan pelayanan kesehatan kepada masyarakat.Para peserta juga aktif bertanya terhadap materi dan soal soal yang diberikan oleh pematari.Mereka bertanya tidak harus diakhir pertemuan atau pada pengerjaan soal.Tetapi jika mereka langsung menanyakan jika mereka tidak paham bahkan meminta untuk diajarkan secara langsung.Para narasumber dan mahasiswa selalu mendampingi peserta dengan kesabaran, ketelititian dan tanggung jawab.Agar materi yang disampaikan secara keselurauhan bisa dimengerti dan peserta menguasai materi dengan baik. Melalui workshopini juga mampu meningkatkan kemampuan dasar peserta dalam menggunakan perangkat lunak microsoft office, khususnya dalam membantu menyelesaikan berbagai jenis pekerjaan yang ada.

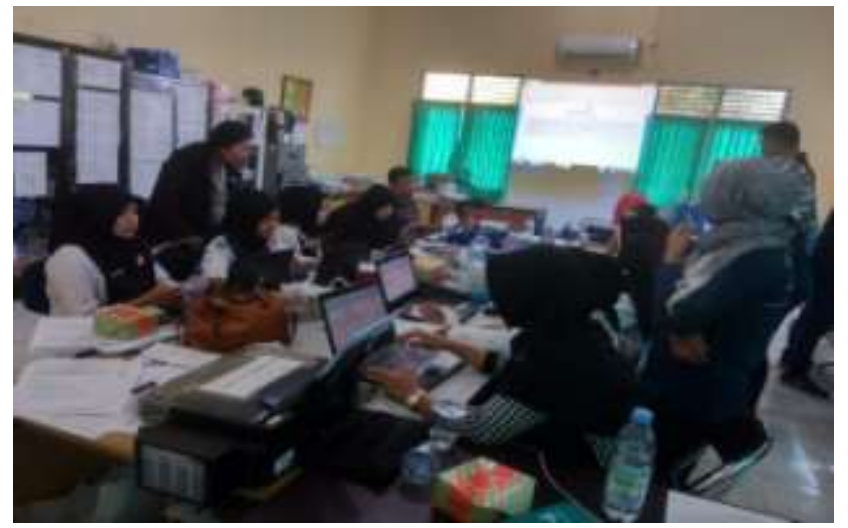

Gambar 5. Pemateri dan mahasiswa memberikan bantuan pendampingan terhadap perserta 


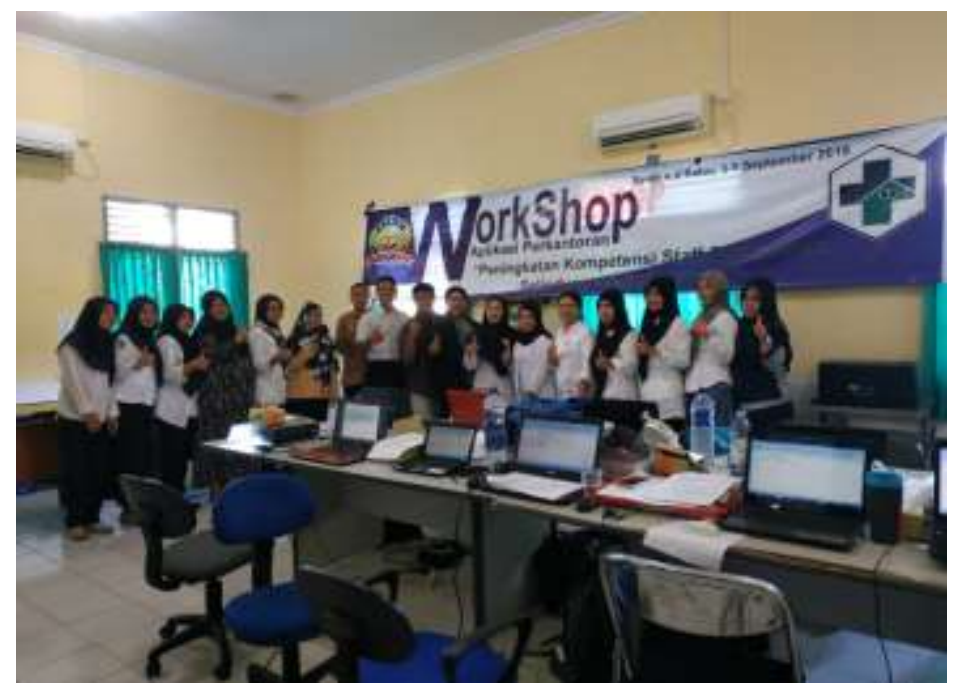

Gambar 6. Foto bersama satu dengan para peserta dan Pemateri

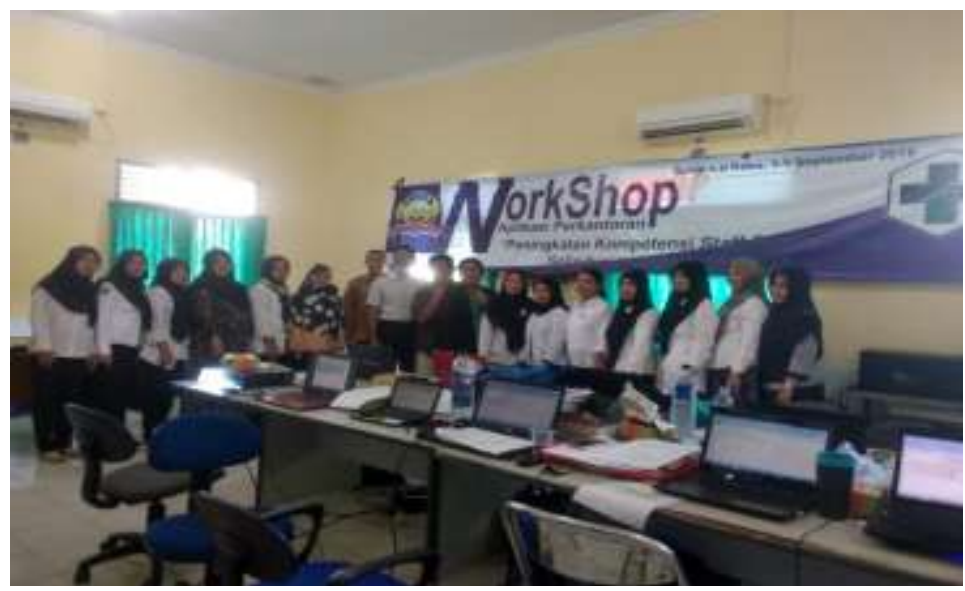

Gambar 7. Foto bersama satu dengan para peserta dan Pemateri

\section{Kesimpulan}

Kegiatan workshop aplikasi perkantoran di puskesmas Selindung berlangsung selama tiga hari, diharapkan memberikan perubahan yang postif dalam penggunaan aplikasi perkantoran yaitu word, excel dan powerpoint. Semua peserta dapat mengikuti kegiatan workshop ini dengan semangat dan antusias yang tinggi.Hal ini bisa terlhat ada beberapa pertanyaan yang yang disampaikan peserta, pertanyaan tersebut merupakan kendala yang sering mereka hadapi dalam penggunaan aplikasi perkantoran.Diharapakan dengan adanya workshop ini bisa meningkatkan kompetensi dan kemampuan peserta dalam menggunakan aplikasi perkantoran, khususnya dalam menyelesaikan berbagai pekerjaan dan laporan yang di buat. Sehingga informasi yang disampaikan bisa lebih cepat, tepat dan akurat 
GANDRUNG: Jurnal Pengabdian Kepada Masyarakat ISSN: 2721-6136 (Online)

\section{Daftar Referensi}

Adzim, F., \& Rum, E. P. (2017). Berkemajuan : Jurnal Pengabdian Kepada Masyarakat. 1(01), 52-54.

Ali, P. bahjuri, Siahaan, renova glorya montesori, Solikha, dewi amila, \& Wikanestri, I. (2018). Penguatan Pelayanan Kesehatan Dasar di Puskemas. In Direktorat Kesehatan dan Gizi Masyarakat.

https://www.bappenas.go.id/files/1715/3974/8326/Buku_Penguatan_Pelayanan_Kesehatan_Dasa

r_di_Puskesmas-_Direktorat_Kesehatan_dan_Gizi_Masyarakat_Bappenas.pdf

Fadlan, M., \& Saputra, I. T. (2020). Peningkatan Keterampilan Sumber Daya Manusia Pmi Kota

Tarakan Melalui Pelatihan Berbasis Teknologi Informasi. KACANEGARA Jurnal Pengabdian

Pada Masyarakat, 3(2), 175-181. https://doi.org/10.28989/kacanegara.v3i2.669

Google. (n.d.). Puskesmas Selindung.

Kesehatan, M. (2014). Peraturan Menteri Kesehatan Republik Indonesia No 75 Tahun 2014. ukor.kemkes.go.id/uploads/produk_hukum/PMK No. 75 ttg Puskesmas.pdf

Malabay. (2016). Penyuluhan Dan Pelatihan Teknologi Informasi Dalam Rangka Meningkatkan Produktivitas Pembelajaran Di Yayasan Perguruan Birrul Waalidain. Jurnal Abdimas, 2(2), 38-42.

Niati, A., Soelistiyono, A., \& Ariefiantoro, T. (2019). Pengembangan Kemampuan Sumber Daya Manusia melalui Pelatihan Komputer Microsoft Office Excel untuk Meningkatkan Kinerja Perangkat Desa Mranggen. E-Dimas: Jurnal Pengabdian Kepada Masyarakat, 10(1), 105. https://doi.org/10.26877/e-dimas.v10i1.3557

Ningsih, S., \& Dewi, M. W. (2020). Peningkatan Sumber Daya Manusia Melalui Pelatihan Komputer Microsoft Excel Bagi Perangkat Desa Wirogunan. Jurnal BUDIMAS, 02(02), 166-172.

Nurhidayati, N., Asrori, I., Ahsanuddin, M., \& Dariyadi, M. W. (2019). Pembuatan Media Pembelajaran Berbasis Powerpoint Dan Pemanfaatan Aplikasi Android Untuk Guru Bahasa Arab. Jurnal KARINOV, 2(3), 181. https://doi.org/10.17977/um045v2i3p181-184

Permata, E., M, Y. R. D., Irwanto, \& Fatkhurrokhman, M. (2021). Pelatihan Komputer Microsoft Office dan Media Pembelajaran Animasi untuk Meningkatkan Kompetensi Guru SDIT AI Muhajirin. Dinamisia: Jurnal Pengabdian Kepada Masyarakat, 5(2), 413-420. https://doi.org/10.31849/dinamisia.v5i2.5265

Risnawati, R., Handayani, M., \& Anggraini, S. (2020). Pelatihan Pemanfaatan Teknologi Komputer Dalam Pengolahan Data Pasien Pada Upt. Puskesmas Porsea. Jurdimas (Jurnal Pengabdian Kepada Masyarakat) Royal, 3(1), 47-50. https://doi.org/10.33330/jurdimas.v3i1.478

Sari, L. I., Probonegoro, W. A., \& Romadiana, P. (2021). Peningkatan Kualitas SDM Melalui Pelatihan 
GANDRUNG: Jurnal Pengabdian Kepada Masyarakat ISSN: 2721-6136 (Online)

Penggunaan Teknologi Informasi di Desa Air Anyir. JURNAL ABDIDAS, 2(3), 597-602. https://doi.org/https://doi.org/10.31004/abdidas.v2i3.322

Susilo, J., Pujiatna, T., \& Firmasari, S. (2020). Pembinaan Tata Bahasa dan Bentuk Surat-Menyurat Indonesia Berbasis Microsoft di Desa Mandala, Dukupuntang Kabupaten Cirebon. JPPM (Jurnal Pengabdian Dan Pemberdayaan Masyarakat), 4(1), 173. https://doi.org/10.30595/jppm.v0i0.5498 Wayne, R. M. (2008). Manajemen Sumber Daya Manusia. Erlangga- Jakarta.

Yusril, I., Haldi, B., \& Muhammad, R. (2015). Pelatihan Aplikasi Microsoft Word 2013 Pada SMP H.A Johansyah A Banjarmasin. Jurnal Al Ikhlas, 1(1), 11. https://doi.org/10.31764/jpmb.v4i1.2999 